\title{
Tomato SIBL4 plays an important role in fruit pedicel organogenesis and abscission
}

\author{
Fang Yan ${ }^{1,2}$, Zhehao Gong ${ }^{2}$, Guojian $\mathrm{Hu}^{2}$, Xuesong Ma', Runyao Bai ${ }^{1}$, Ruonan Yu', Qiang Zhang ${ }^{3}$, Wei Deng ${ }^{2}$, \\ Zhengguo $\mathrm{Li}^{2,4}$ and Hada Wuriyanghan ${ }^{1}$
}

\begin{abstract}
Abscission, a cell separation process, is an important trait that influences grain and fruit yield. We previously reported that BEL1-LIKE HOMEODOMAIN 4 (SIBL4) is involved in chloroplast development and cell wall metabolism in tomato fruit. In the present study, we showed that silencing SIBL4 resulted in the enlargement and pre-abscission of the tomato (Solanum lycopersicum CV. Micro-TOM) fruit pedicel. The anatomic analysis showed the presence of more epidermal cell layers and no obvious abscission zone (AZ) in the SIBL4 RNAi lines compared with the wild-type plants. RNA-seq analysis indicated that the regulation of abscission by SIBL4 was associated with the altered abundance of genes related to key meristems, auxin transporters, signaling components, and cell wall metabolism. Furthermore, SIBL4 positively affected the auxin concentration in the abscission zone. A dual-luciferase reporter assay revealed that SIBL4 activated the transcription of the JOINTLESS, OVATE, PIN1, and LAX3 genes. We reported a novel function of SIBL4, which plays key roles in fruit pedicel organogenesis and abscission in tomatoes.
\end{abstract}

\section{Introduction}

Organ abscission is critical for plant growth and development, as it enables the recycling of nutrients for continuous growth, development of appropriate organs, survival in case of disease, and reproduction ${ }^{1,2}$. Plant organ shedding refers to the abscission of some plant organs, such as flowers, leaves, fruits, and other tissues; it is caused by the coordinated actions of physiological processes, biochemical metabolism, and gene regulatory networks ${ }^{3}$. Abscission occurs at predetermined positions called abscission zones (AZs), and the abscission process includes differentiation of the $\mathrm{AZ}$, acquisition of the competence to respond to abscission signals, activation of organ abscission, and formation of a protective layer ${ }^{4-7}$.

\footnotetext{
Correspondence: Zhengguo Li (zhengguoli@cqu.edu.cn) or

Hada Wuriyanghan (nmhadawu77@imu.edu.cn)

${ }^{1}$ Key Laboratory of Herbage \& Endemic Crop Biotechnology, Ministry of Education, School of Life Science, Inner Mongolia University, Hohhot 010021, China

${ }^{2}$ Key Laboratory of Plant Hormones and Development Regulation of

Chongqing, School of Life Sciences, Chongqing University, 401331 Chongqing, China
}

Full list of author information is available at the end of the article
Abscission initiation is considered to be triggered by the interaction of two hormones, auxin and ethylene ${ }^{8-10}$. During the late abscission stages, several key enzymes play an important role in organ shedding. Cellulase (Cel) and polygalacturonase (PG) participate in the degradation of the cell wall, and pectin methylesterase (PME) changes the chemical structure of the AZ via hydrolysis and induces cell wall and membrane degradation ${ }^{11}$.

Genetic analyses of tomato (Solanum lycopersicum) have revealed that many transcription factors (TFs) are involved in AZ differentiation and abscission. JOINTLESS was shown to be directly related to the development of flower pedicels, inflorescence structure, fruit shape, and seed development, and the jointless mutant failed to develop $\mathrm{AZs}^{12,13}$. In addition to JOINTLESS, jointless-2 delayed the development and formation of tomato $\mathrm{AZs}^{13}$. Two MADS-box genes, Macrocalyx $(M C)$ and SIMBP21, regulate pedicel AZ development, and the knockdown of these genes results in a jointless phenotype ${ }^{14,15}$. BLIND $(B l)$, a R2R3-class MYB TF gene, genetically interacts with JOINTLESS and plays an important role in abscission $^{14,16,17}$. Lateral suppressor (Ls) partially impairs AZ

\section{(c) The Author(s) 2021}

(c) (i) Open Access This article is licensed under a Creative Commons Attribution 4.0 International License, which permits use, sharing, adaptation, distribution and reproduction cc) in any medium or format, as long as you give appropriate credit to the original author(s) and the source, provide a link to the Creative Commons license, and indicate if changes were made. The images or other third party material in this article are included in the article's Creative Commons license, unless indicated otherwise in a credit line to the material. If material is not included in the article's Creative Commons license and your intended use is not permitted by statutory regulation or exceeds the permitted use, you will need to obtain permission directly from the copyright holder. To view a copy of this license, visit http://creativecommons.org/licenses/by/4.0/. 
development and causes malformation of meristem axillary buds. Furthermore, tomato $l s$ mutants lack petals in their flowers ${ }^{18}$. BLADE ON PETIOLE1/2 (BOP1 and $B O P 2)$ were shown to be involved in the formation of Arabidopsis thaliana floral organ AZs, and the floral organs failed to abscise in the bop1/bop 2 double mutant ${ }^{19}$.

The three-amino-acid-loop-extension (TALE) class genes encode TFs, such as KNOTTED-like (KNOX) and BEL1like (BLH, BELL), and are typically involved in the regulation of meristematic activity ${ }^{20}$. TALE homeobox genes not only mediate plant development but also participate in plant organ separation. In A thaliana, several members of the TALE family are reported to play central roles in regulating pedicel development. The KNAT/BP gene affects the development of $A$. thaliana floral AZs. In the $b p$ mutant, the floral organs form more follicular cells and are abscised early due to the increased expression of KNAT2 and KNAT6 in the pedicel ${ }^{21-23}$. A. thaliana homeobox gene 1 (ATH1), a BELL TF member, plays a key role in the KNAT2 pathway to regulate pedicel development ${ }^{24}$. PENNYWISE (PNY) and POUND-FOOLISH (PNF) form heterodimers with KNOX proteins to regulate flowering initiation and inflorescence architecture $^{25-28}$. SlBL4, a tomato bell-like gene, was shown to target chlorophyll synthesis and cell wall metabolism genes to control chloroplast development and cell wall metabolism in tomato fruit ${ }^{29}$. The expression of SlBL4 was upregulated in $\mathrm{AZs}^{10}$, and SlBL4 has high sequence similarity with $\mathrm{ATH}{ }^{29}$, suggesting that it plays an important role in tomato pedicel AZ development.

Tomato is an excellent model for the study of the AZ, as it has distinct fruit/flower pedicels, rich genetic resources, and a stable genetic background. The present work identified a previously undefined role of the tomato BELL family gene bell-like homeodomain protein 4 (SlBL4) in the development of fruit pedicels. The pedicel AZ expanded more after anthesis, and the rate of fruit abscission was significantly increased starting from the abscission day in SlBL4 RNAi plants compared with WT plants. AZ transcriptomic and physiological analyses showed that the SIBL4 protein might play a role in the initiation and abscission of tomato AZs by regulating a variety of gene families and cell wall substructures.

\section{Materials and methods}

\section{Plant material and growth conditions}

Micro-Tom tomato plants (Solanum lycopersicum) were grown under greenhouse conditions with a $16 \mathrm{~h}$ light $\left(25^{\circ} \mathrm{C} \pm 2{ }^{\circ} \mathrm{C}\right) / 8 \mathrm{~h}$ dark $\left(18{ }^{\circ} \mathrm{C} \pm 2{ }^{\circ} \mathrm{C}\right)$ cycle and $80 \%$ relative humidity with $250 \mu \mathrm{mol} \mathrm{m}^{-2} \mathrm{~s}^{-1}$ of intense light.

\section{Quantitative RT-PCR (qRT-PCR) analysis, plant binary vector construction, and tomato transformation}

For the expression analysis of SlBL4 in tomato pedicels at different stages, the materials were collected, immediately frozen in liquid nitrogen, and stored at $-80^{\circ} \mathrm{C}$ for RNA extraction. Gene-specific primers are listed in Table S1. qRT-PCR was carried out as described previously ${ }^{30}$.

The promoter sequence of SlBL4 was amplified from tomato genomic DNA with the primers SlBL4-PF and SlBL4-PR (Table S1). The promoter fragment of SlBL4 was digested with $\mathrm{Sal} \mathrm{I} / \mathrm{BamH} \mathrm{I}$ and ligated into the plant binary vector pLP100 containing the GUS reporter gene, yielding the reporter vector pLP100pSlBL4-GUS. Transgenic plants were obtained by the Agrobacterium-mediated transformation method ${ }^{31}$. The transgenic lines were selected and confirmed by $\mathrm{qPCR}$ and GUS staining according to the methods of $\mathrm{Yan}^{32}$. The SlBL4-RNAi plants were obtained according to the method of a previous study ${ }^{29}$. Three representative transgenic lines (L19, L22, and L23) were selected for further analysis, and all experiments were performed using homozygous lines of the $\mathrm{T}_{3}$ generation.

\section{Auxin and ethylene treatment}

For auxin treatment, tomato seeds $(n=30)$ from the wild type (WT) and SlBL4 RNAi lines were soaked in MS medium supplemented with different concentrations $(0$, $0.25,0.5$, and $1 \mu \mathrm{M}$ ) of indole-3-acetic acid (IAA) (Sigma, USA) for 14 days in a culture chamber. Primary and lateral root numbers and lengths were measured, and photographs were taken after 14 days of growth. For ethylene treatment, the same seeds were soaked in MS medium supplemented with $1 \mu \mathrm{M}$ ACC for 7 days in the dark culture chamber as described above. Root and hypocotyl elongation were observed and measured after 7 days of growth. All experiments were independently repeated at least three times.

Floral explants were prepared by excising freshly opened flowers, including the pedicel AZ. For the IAA treatment, the pedicel ends of explants were inserted into a layer of $1 / 2$ MS agar with $50 \mu \mathrm{g} / \mathrm{g}$ IAA in a Plexiglass box and placed in a tray filled with a layer of water. For the ethylene treatment, the pedicel ends of explants were treated similarly, but ethylene gas was added to the box at a final concentration of $20 \mu \mathrm{l} / \mathrm{L}$. The abscised pedicel explants were counted at 8 , $16,24,32,40,48,56,64,72,84,96,108$, and $120 \mathrm{~h}$ after treatment. Three biological replicates were performed, and each treatment group contained $\sim 50$ explants.

\section{GUS Staining and auxin content measurement}

Tomato inflorescences were placed into GUS staining buffer comprising $2.0 \mathrm{mM}$ 5-bromo-4-chloro-3-indolyl-bglucuronic acid, $0.1 \mathrm{M} \mathrm{Na}_{3} \mathrm{PO}_{4}(\mathrm{pH} 7.0), 1.0 \mathrm{mM} \mathrm{K}_{3} \mathrm{Fe}$ $(\mathrm{CN})_{6}, 10 \mathrm{mM} \mathrm{Na}{ }_{2}$ EDTA and $0.1 \%$ (v/v) Triton X-100. The inflorescences were vacuumed for $30 \mathrm{~min}$ and incubated in the dark at $37^{\circ} \mathrm{C}$ for $16 \mathrm{~h}$. GUS-stained tissues were washed with $70 \%(\mathrm{v} / \mathrm{v})$ ethanol and observed under a light microscope. 
Floral explants including the pedicel AZ were prepared by excising the tissues at 6,4 , and 2 days before anthesis (dba), on the anthesis day, and at 2 and 25 days post anthesis (dpa). For IAA treatment, the pedicel ends of explants were inserted into a layer of $1 / 2 \mathrm{MS}$ agar with $50 \mu \mathrm{g} / \mathrm{g}$ IAA, and the floral explants were stained with GUS after $24 \mathrm{~h}$ of treatment.

The IAA content was measured by acquisition ultraperformance liquid chromatography (Acquity UPLC; Waters). Fifty pedicel AZ segments were collected from the pedicel at the abscission stage, immediately frozen in liquid nitrogen, and stored at $-80^{\circ} \mathrm{C}$ for IAA quantification according to the literature ${ }^{33}$.

\section{Microscopy and TEM observation}

For histological analysis, tissue samples were collected from the pedicel at $25 \mathrm{dpa}$ and immersed in FAA solution, placed under vacuum for $15 \mathrm{~min}$, and incubated at $25^{\circ} \mathrm{C}$ for $72 \mathrm{~h}$. The samples were dehydrated, stained, and observed under a microscope according to the literature $^{32}$. At anthesis, flowers of WT plants and SlBL4 RNAi line tomatoes were emasculated and subsequently counted and sampled for anatomical assessment at $10 \mathrm{dpa}$. For the histological assessment of SlBL4pro::GUS expression, tissue samples were collected from the pedicel of pSlBL4GUS transgenic tomato at the following times: at 6, 4, $2 \mathrm{dba}$; on the anthesis day; and at 2, $25 \mathrm{dpa}$. The pedicel of the $\mathrm{AZ}$ at $25 \mathrm{dpa}$ was observed by transmission electron microscopy (TEM) according to the literature ${ }^{34}$.

\section{RNA-seq analysis}

Pedicel samples, including those at three stages (0 dpa, $25 \mathrm{dpa}$, and the fruit break stage), were dissected using a sharp razor blade into three segments (distal, $\mathrm{AZ}$, and proximal tissues), and an AZ segment of $\sim 2 \mathrm{~mm}$ was placed in liquid nitrogen immediately. Total RNA was extracted using the RNeasy Plant Mini Kit (Qiagen, USA) according to the manufacturer's instructions. Three biological replicates were performed for each sample for both SlBL4-RNAi and WT plants. The RNA-Seq libraries were constructed and sequenced on the Illumina HiSeq 2000 platform at the Wuhan Genome Institute (BGI, China). The raw sequences were processed by removing the adaptor and low-quality sequences. The expression levels of DEGs were normalized by the fragments per kilobase of exon per million mapped reads (FRKM) method using Cuffdiff software (http://cole-trapnell-lab.github.io/ cufflinks/). A false discovery rate (FDR) $\leq 0.05$ was used to determine the threshold for DEGs. GO functional enrichment and KEGG pathway analyses were conducted according to previously described methods (https://github.com/tanghaibao/goatools) and KOBAS (http://kobas.cbi.pku.edu.cn/home.do).

\section{Dual-luciferase transient expression assay}

For effector vector construction, the full-length coding sequence of SlBL4 was amplified and then cloned into the pEAQ-Empty vector ${ }^{29}$. For reporter vector construction, the promoters of the JOINTLESS, OVATE, LAX3, and PIN1 genes were cloned into a pGreenII 0800-LU vector $^{35}$. A dual-luciferase transient expression assay for SIBL4 was carried out using tobacco leaves (Nicotiana benthamiana). A dual-luciferase assay kit (Promega, USA) was used to measure the activities of LUC and REN luciferase according to the manufacturer's instructions on a Luminoskan Ascent microplate luminometer (Thermo Fisher Scientific, USA). Six biological repeats were performed for each pair of vector combinations. The primer sequences used for the vector construct are shown in Table S1.

\section{Results}

SIBL4 expression is associated with AZ development

$S l B L 4$ was reported to be predominately expressed in pedicel AZs in tomato ${ }^{10}$. To clarify the involvement of SlBL4 in tomato pedicel abscission, the transcript level of SIBL4 was analyzed in pedicel AZs from the floral bud stage to the flowering stage ( 2 days before anthesis, $2 \mathrm{dba}$; anthesis day, AS; 2 days post anthesis, 2 dpa) by qRT-PCR. The transcript levels of SlBL4 showed progressive increases at $2 \mathrm{dba}$, AS and $2 \mathrm{dpa}$ (Fig. 1A). Furthermore, pSlBL4-GUS transgenic tomato was generated according to the literature ${ }^{32}$. Consistent with the qRT-PCR results, GUS expression was obviously visible in the AZ and showed an increasing expression pattern during anthesis development (Fig. 1B). The anatomic analysis was performed to more precisely assess the SlBL4 expression pattern in the AZ. The results showed that GUS expression was obviously visible in the whole pedicle before anthesis and increased after anthesis in the pedicle AZ (Fig. 1C-H). This AZ-specific expression pattern indicated that SlBL4 possibly participated in the abscission process.

\section{Silencing SIBL4 augmented the pedicel and promoted abscission}

In this study, we used a 35S::SlBL4-RNAi silencing construct to generate SlBL4 knockdown Micro-Tom tomato plants. The transgenic tomato exhibited SlBL4 expression that was reduced by $20-80 \%$ compared with that of the WT plant ${ }^{29}$. At 25 days after flowering, the floral pedicel AZ expanded to a greater extent in SlBL4 knockdown plants than in the control WT plants, whereas no obvious difference was found at the anthesis stage (Fig. 1C-F). The AZ diameters were $3.76-4.26 \mathrm{~mm}$ in the three SlBL4 RNAi lines and 39-57\% higher than those in the WT plants at 25 days after flowering (Fig. 1E, F). 


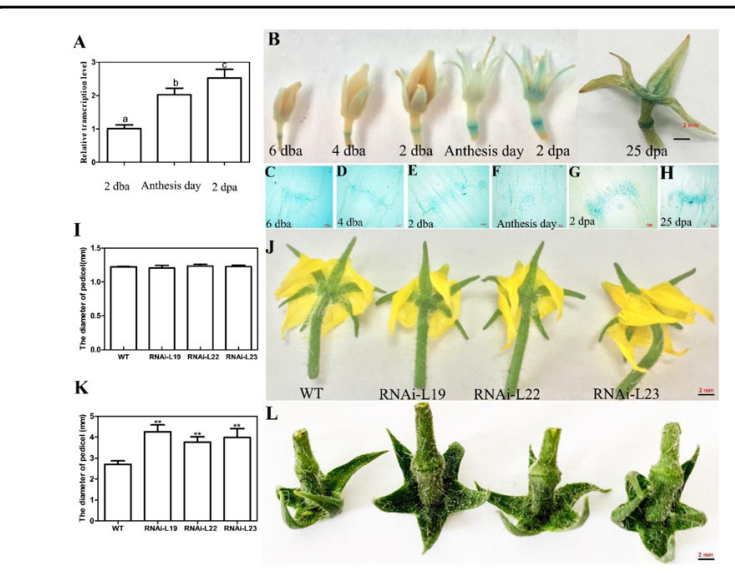

Fig. 1 Expression analysis of SIBL4 and the pedicel abscission phenotype of the RNAi plants. A Expression analysis of SIBL 4 in different stages of tomato pedicel abscission; $2 \mathrm{dba}, 2$ days before anthesis; 2 dpa, 2 days post anthesis. The quantitative PCR data represent mean values for three independent biological replicates, and Duncan's multiple range test was performed to compare samples in different groups. The standard errors are indicated by vertical bars. B SIBL4pro::GUS expression at 6, 4, 2 dba: 6, 4, and 2 days before anthesis; anthesis day; 2, 25 dpa: 2 and 25 days post anthesis; $\mathbf{C}-\mathbf{H}$ Anatomic analysis of the floral pedicel abscission zone of SIBL4pro::GUS plants: C 6 dba; D 4 dba; I 2 dba; $\mathbf{F}$ anthesis day; $\mathbf{G} 2$ dpa; $\mathbf{H} 25 \mathrm{dpa}$. I The diameter of the pedicel abscission zone on the anthesis day. $\mathbf{J}$ Anthesis day pedicel. $\mathbf{K}$ The diameter of the pedicle abscission zone on 25 dpa. $\mathbf{L} 25$ dpa pedicel. WT wild type, RNAi-L19, RNAi-L22, RNAi-L23 three different lines of SIBL4 RNAi plants. Scale bars: $2 \mathrm{~mm}$

In emasculated flowers, the pedicel abscised at 10 and 14 days after emasculation in the RNAi lines and WT plants, respectively (Fig. 2A). Anatomic analysis of the floral pedicel $\mathrm{AZ}$ at 10 days after emasculation showed that the unpollinated flowers were abscised in the $\mathrm{AZ}$ in the SlBL4 RNAi lines, but the cells began to separate at the AZ in the WT plants (Fig. 2B, C).

Sexton and Roberts reported that auxin and ethylene participate in the regulation of abscission in dicotyledonous plants ${ }^{36}$. To analyze the effect of IAA on RNAi line flower abscission, flowers were removed and replaced by $1 / 2 \mathrm{MS}$ containing $50 \mu \mathrm{g} / \mathrm{g}$ IAA. The explants began to abscise at $8 \mathrm{~h}$ in the RNAi lines but at $16 \mathrm{~h}$ in the WT plants without IAA treatment, whereas they began to abscise at $24 \mathrm{~h}$ in the RNAi lines but at $36 \mathrm{~h}$ in the WT plants after IAA treatment (Fig. 2D, E). These results demonstrated that the RNAi lines exhibited an earlyabscission phenotype and that IAA treatment could rescue this phenotype. For ethylene $(20 \mu \mathrm{L} / \mathrm{L})$ treatment of the explants, there was no difference between the RNAi lines and the WT plant in terms of the abscission rate (Fig. S1).

To investigate whether the downregulation of SlBL4 alters auxin sensitivity, the root phenotype was further investigated. The RNAi lines exhibited shorter primary roots after IAA treatment compared with those of the WT seedlings. Lower lateral root numbers were observed in the RNAi lines after 0.5 and $1.0 \mu \mathrm{M}$ IAA treatment compared with those of the WT seedlings (Fig. 2F-K). There was no difference between the RNAi lines and WT plant seedlings treated with $1 \mu \mathrm{M}$ ACC for 7 days in the dark culture chamber (data not shown). These results suggested that the SlBL4 RNAi tomato plants were sensitive to auxin in terms of root growth.

Anatomic analysis of the floral pedicel AZ showed that no obvious $\mathrm{AZ}$ formed, and more epidermis cell layers were observed in the SlBL4 RNAi lines than in the WT (Fig. 3A-F). The epidermal cell layers and cell diameter were obviously increased by $90 \%$ and $36 \%$, respectively, in the floral pedicel AZ of the SlBL4 RNAi lines compared with the WT plants (Fig. 3G, H). Scanning electron microscopy (SEM) observations showed that epidermal cells were enlarged in the SlBL4 RNAi lines compared with the WT (Fig. 3I, J). Silencing SlBL4 positively affected the formation of pedicels in tomato plants. At the break (Br) stage, the fruit began to drop earlier in the SlBL4 RNAi lines than in the WT plants (Fig. 4A and C-F). The ratio of fruit abscission was significantly increased on different Br days in SlBL4 RNAi plants, whereas no fruit dropping was observed in the WT plants at the same stage (Fig. 4B). These observations indicated that the suppression of SlBL4 activated pedicel abscission.

\section{RNA-seq and DEG analyses of pedicels of SIBL4 RNAi lines and wild-type plants}

RNA-seq was performed to investigate the transcriptional mechanisms underlying the phenotype of thickened and pre-abscission pedicels in the SlBL4 RNAi-L19 plant. DEGs (differentially expressed genes) were obtained for SlBL4 RNAi-L19 plants compared with the WT plant in the AZ at the AS, $25 \mathrm{dpa}$, and $\mathrm{Br}$ stages. Correlation analysis and PCA demonstrated that the RNA-seq data for the RNAi-L19 plant pedicel samples were clearly differentiated from those for the WT plants at the $25 \mathrm{dpa}$ and Br stages with good repeatability (Fig. S2 and Fig. 5A). The DEGs were categorized into three major classes, namely, cellular components, molecular functions, and biological processes, by GO annotation (Fig. S3A-C). KEGG pathway analysis showed that the DEGs were involved in metabolism, genetic information processing, and organismal systems (Fig. S3D-F). Under the criterion of a FDR $\leq 0.001,329$ DEGs were commonly upregulated or downregulated at the three developmental stages of tomato (Fig. 5B). In SlBL4 RNAi AZs, 623, 1809, and 3500 genes were upregulated, and 397, 955, and 1580 genes were downregulated, respectively, at the anthesis day, 25 dpa, and Br stages compared with the WT plant (Fig. 5C). Cluster analysis showed that the DEGs were associated with the auxin-activated signaling pathway, the cellular 

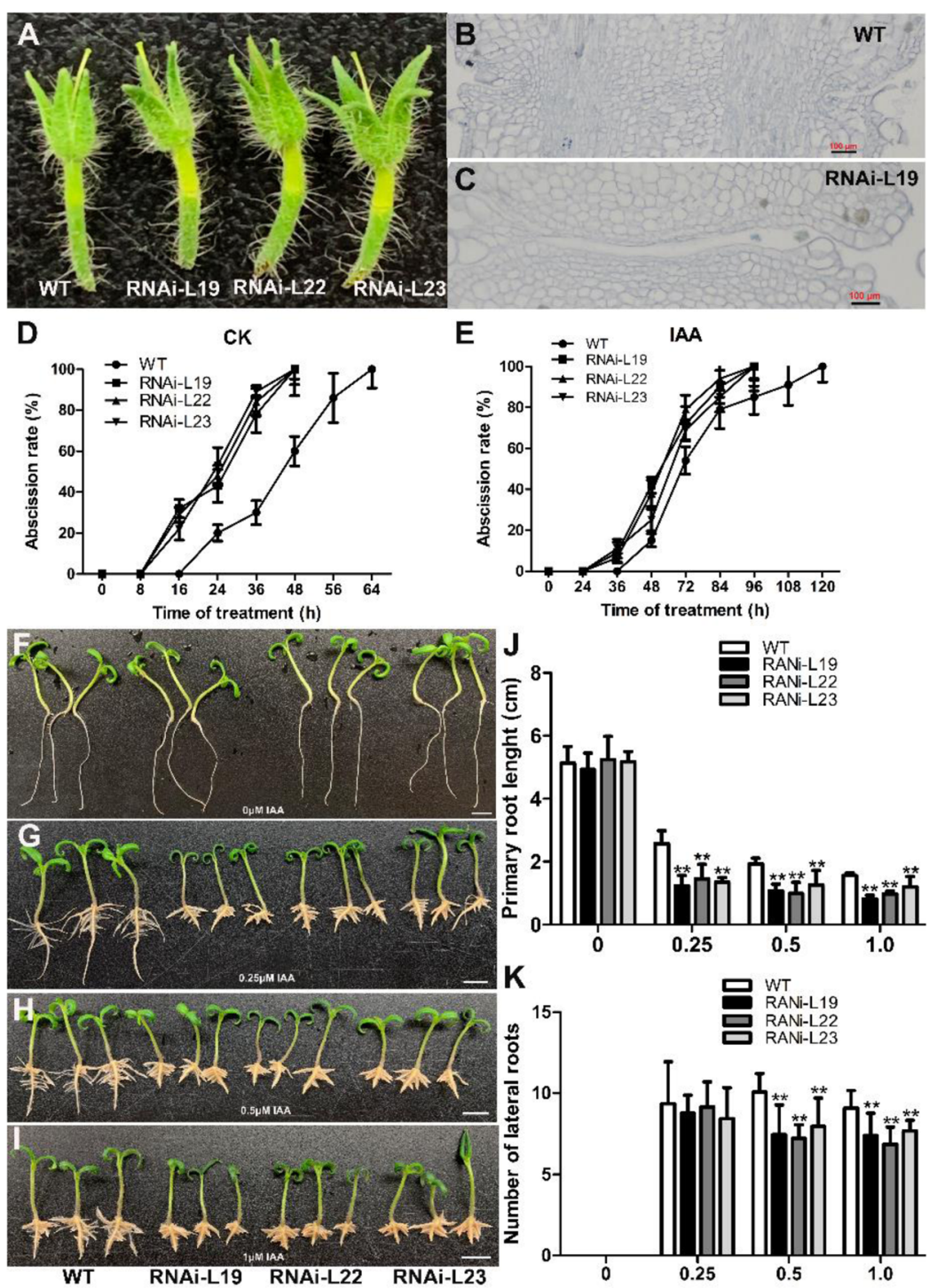

Fig. 2 Effects of exogenous auxin on SIBL4 RNAi plants. A Phenotypes of flower droppings after emasculation at 10 days. B, C Microsection of a 10-day floral pedicel abscission zone after emasculation in RNAi plants and WT tomato. D, E Abscission rate; D Timing of floral abscission-zone explants of tomato flowers following exposure to 1/2 MS; E Timing of floral abscission-zone explants of tomato flowers following exposure to $1 / 2$ MS with $50 \mathrm{\mu g} / \mathrm{g}$ IAA. F-I Root development in WT plants and three independent SIBL4 RNAi lines (L19, L22, and L23) assessed in two-week-old seedlings grown on $1 / 2 \mathrm{MS}$ medium containing different concentrations of IAA $(0,0.25,0.5$, and $1.0 \mu \mathrm{M})$. $\mathbf{J}$ The lengths of primary roots in the SIBL4 RNAi lines (L19, L22, and L23). K The lateral root numbers in the SIBL4 RNAi lines (L19, L22, and L23); WT wild type, RNAi-L19, RNAi-L22, and RNAi-L23 three different lines of SIBL4 RNAi plants. The asterisks indicate significant differences at $\left.P<0.01{ }^{* *}\right)$ as determined by the $t$-test

glucan metabolic process, cell wall organization, light harvesting, photosynthesis, and protein-chromophore linkage (Fig. 5D and Tables S2-7).

\section{SIBL4 regulates the small cells of pedicel AZs}

The silencing of SlBL4 caused enlargement of the epidermal cells and disappearance of small cells at the separation zone compared with the WT plant (Fig. 3). In the transcriptomic analysis, the expression of wuschel (WUS), cup-shaped cotyledon 2 (CUP2), JOINTLESS and ovate family proteins was decreased significantly, and $B l$, $M Y B$ transcription factor (MYB78), and $L O B$ domain protein 1 ( $L B D 1)$ were substantially upregulated in the SlBL4 RNAi line compared with the WT plant at the abscission stage (Table 1). WUS (Solyc02g083950), CUP (Solyc07g06284), JOINTLESS (Solyc11g010570), and OVATE (Solyc02g085500) were downregulated by 4.3-, 1.77-, 1.09-, and 2.17-fold, and $B l$ (Solyc11g069030), MYB78 (Solyc05g053330), and LBD1 (Solyc11g072470) were upregulated by 4.57-, 3.39-, and 4.8-fold, respectively. 

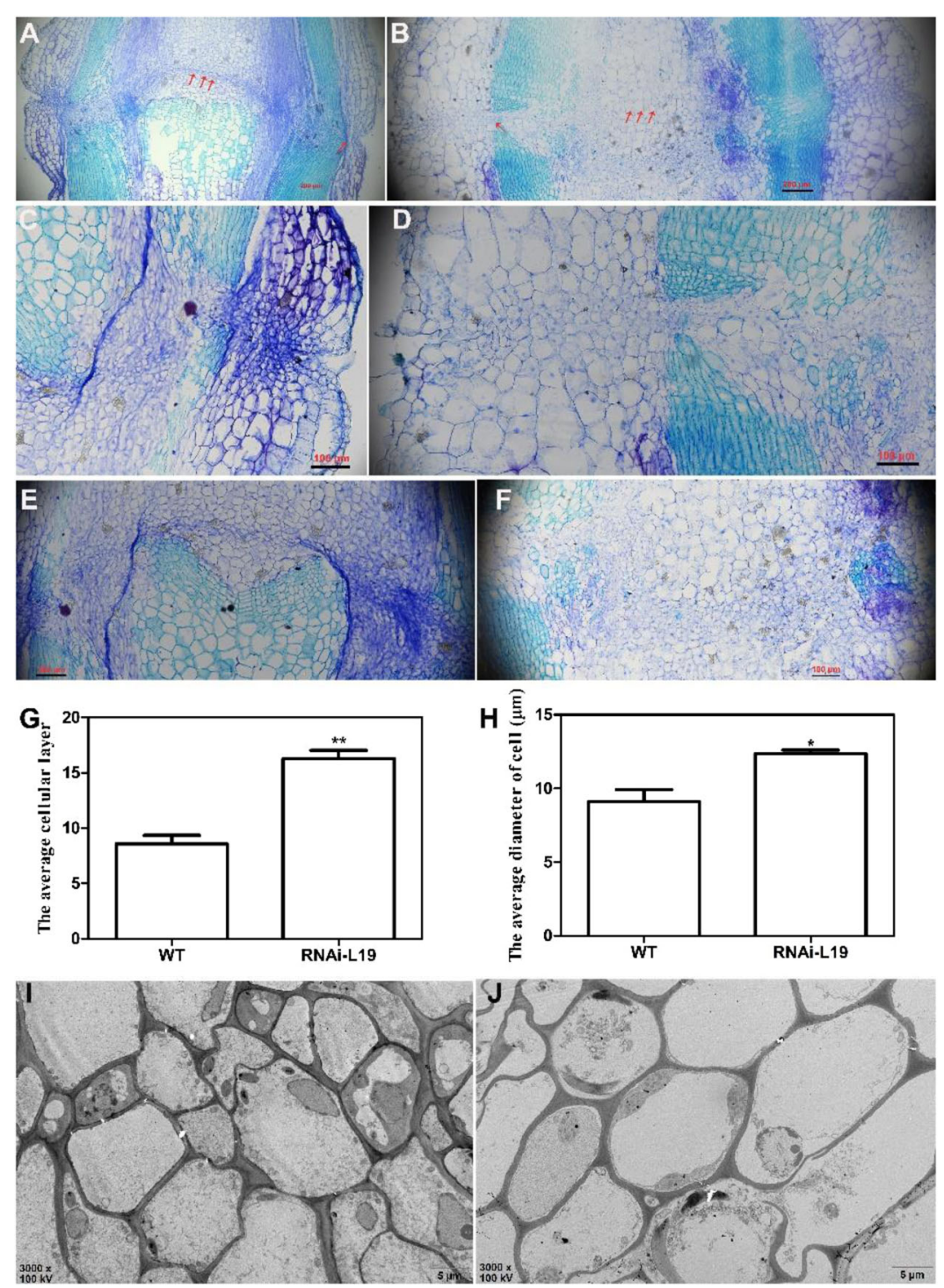

Fig. 3 Anatomic analysis of the fruit pedicel abscission zone of the SIBL4 RNAi plant. A-F Cross-sections of the fruit pedicel abscission zone at the 25 dpa stage as revealed by toluidine blue staining. A, C, E WT; B, D, and F SIBL4 RNAi-L19. G, H The epidermal cell layers per cell in the fruit pedicel abscission zone of $25 \mathrm{dpa}$ fruit pedicels in WT and SIBL4 RNAi-L19 plates; $\mathbf{H}$ The epidermal diameter per cell in the fruit pedicel abscission zone of 25 dpa fruit pedicels in WT and SIBL4 RNAi-L19 plants. I, J Transmission electron micrographs of the fruit pedicels of SIBL4 RNAi-L19 and WT tomato at 25 dpa; I WT; J SIBL4 RNAi-L19; scale bars: $5 \mu \mathrm{m}$; dpa day post anthesis, WT wild type

Thus, these seven TF genes were likely involved in the regulation of abscission onset in the SIBL4 RNAi plant. These genes were vital for maintaining undifferentiated cells in the $\mathrm{AZ}$ of tomato.

To examine the potential target genes of SIBL4 in fruit pedicel development, the promoter sequences were analyzed in JOINTLESS and OVATE, which revealed the SIBL4 binding (G/A) GCCCA (A/T/C) motif ${ }^{29}$. Transient dualluciferase assays were performed to examine whether SlBL4 could directly activate or suppress the expression of the JOINTLESS and OVATE genes. Tobacco leaves were cotransformed with LUC reporter vectors driven by the promoters of the JOINTLESS and OVATE genes together with effector vectors carrying the CaMV35S promoterdriven SlBL4 gene. Transient dual-luciferase assays showed that overexpression of SlBL4 significantly increased the luciferase activity driven by the promoters of JOINTLESS and OVATE compared with that of the empty control (Fig. $6 \mathrm{~A}, \mathrm{~B})$, indicating that SlBL4 activated the transcription of JOINTLESS and OVATE. The expression levels of WUS, $C U P$, and $B l$ were determined by RT-qPCR, and the results coincided with the RNA-seq results (Fig. S4). 

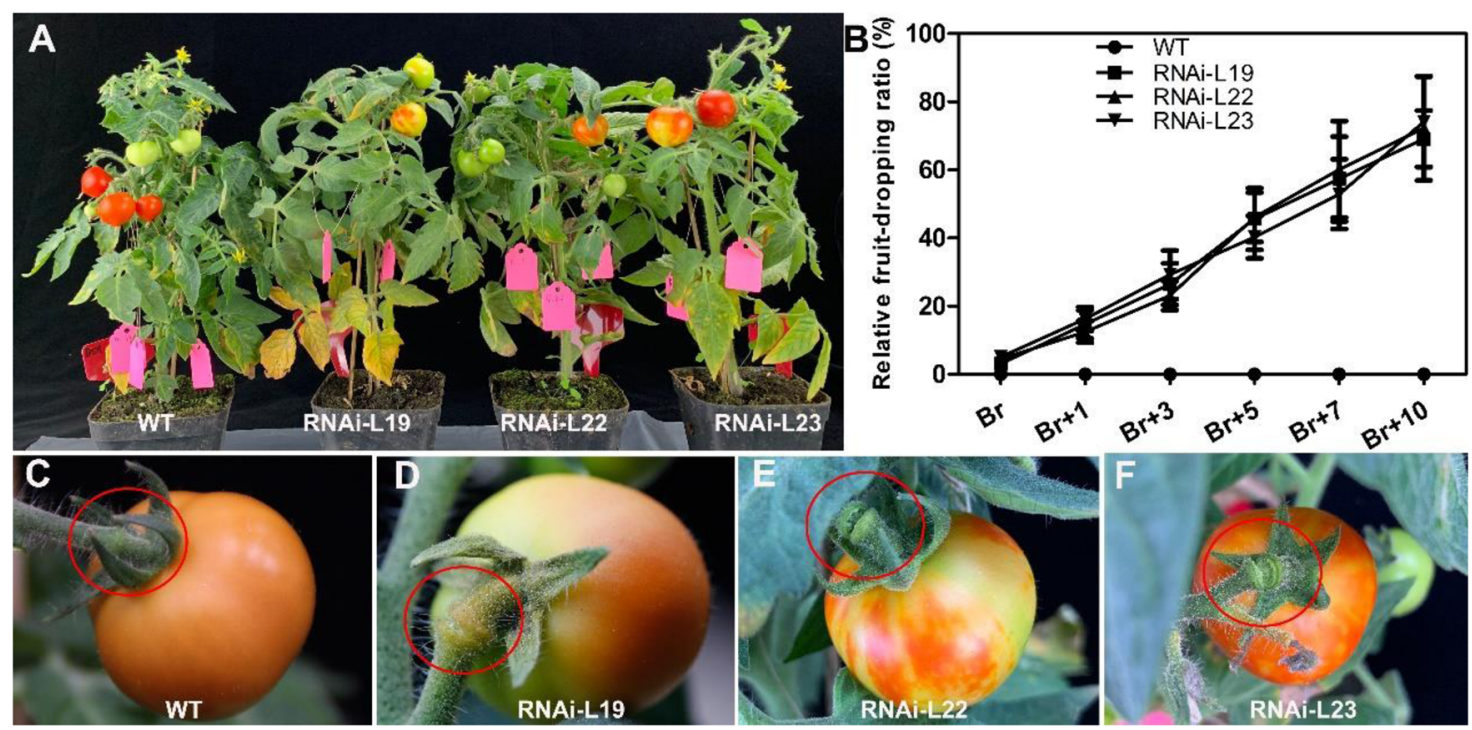

Fig. 4 The fruit-dropping phenotypes of the SIBL4 RNAi plants. A, C-F The fruit-dropping phenotypes. B Fruit-dropping statistical data. WT wild type,RNAi-L19, RNAi-L22, and RNAi-L23 three different lines of SIBL4 RNAi plants

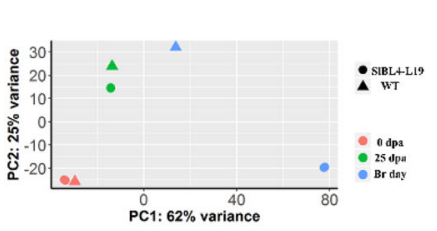

$\mathbf{A}$

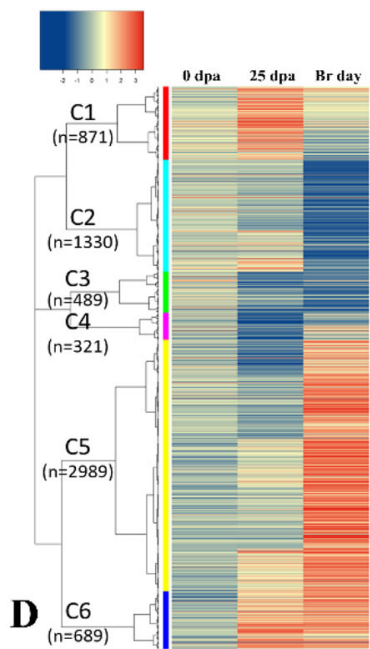

B
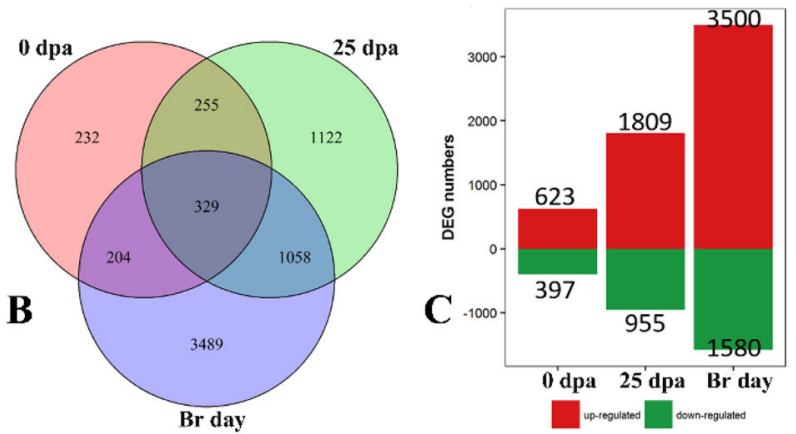

\section{Cluster ID}

C1

C1

photosynthesis

protein import into nucleus

auxin-activated signaling pathway

transcription, DNA-templated

\begin{tabular}{|c|c|}
\hline C3 & no \\
\hline C4 & recognition of pollen \\
\hline C5 & $\begin{array}{l}\text { carbohydrate metabolic process } \\
\text { cellular glucan metabolic process } \\
\text { cell wall organization }\end{array}$ \\
\hline C6 & $\begin{array}{l}\text { photosynthesis, light harvesting } \\
\text { protein-chromophore linkage }\end{array}$ \\
\hline
\end{tabular}

Fig. 5 The DEG analysis of SIBL4 RNAi line 19 compared with wild-type tomato. A Principal component analysis (PCA) of gene expression data from the RNA-seq libraries. B Venn diagram of the differentially expressed genes (DEGs) between SIBL4 RNAi and wild-type plants at three different fruit pedicel stages. C Upregulated (red bar) and downregulated (green bar) DEGs between SIBL4 RNAi and wild-type plants at the three developmental stages of fruit pedicel. D Cluster analysis of DEGs at the three developmental stages of fruit pedicel 
Table 1 Differentially expressed genes in the fruits of wild type and SIBL4 RNAi plants at three stages of development

\begin{tabular}{|c|c|c|c|c|c|c|c|}
\hline \multirow[t]{2}{*}{ Gene ID } & \multirow[t]{2}{*}{ Annotation } & \multicolumn{3}{|c|}{ Fold change $(\log 2)$} & \multicolumn{3}{|l|}{$p$-value } \\
\hline & & $0 \mathrm{~d}$ & $25 d$ & $\mathrm{Br}$ & $0 \mathrm{~d}$ & $25 d$ & $\mathrm{Br}$ \\
\hline \multicolumn{8}{|l|}{ Transcription factor } \\
\hline Solyc02g083950 & Wuschel (WUS) & -1.41 & -1.42 & -4.30 & $<0.001$ & $<0.001$ & $<0.001$ \\
\hline Solyc07g062840 & Protein CUP-SHAPED COTYLEDON 2 (CUP) & -0.42 & -0.40 & -1.77 & 0.113 & 0.285 & $<0.001$ \\
\hline Solyc11g010570 & JOINTLESS & 0.05 & 0.40 & -1.09 & 0.747 & $<0.001$ & $<0.001$ \\
\hline Solyc02g085500 & Ovate family protein & 0.13 & 0.26 & -2.17 & 0.201 & 0.002 & $<0.001$ \\
\hline Solyc1 1g069030 & MYB transcription factor (BLIND) & -1.03 & -0.03 & 4.57 & 0.007 & 0.977 & $<0.001$ \\
\hline Solyc05g053330 & MYB transcription factor (MYB78) & -0.83 & -1.4 & 3.39 & $<0.001$ & $<0.001$ & $<0.001$ \\
\hline Solyc11g0 72470 & LOB domain protein 1 & -1.35 & -0.54 & 4.80 & $<0.001$ & 0.063 & $<0.001$ \\
\hline Solyc05g010000 & IDA & -1.34 & 0.000 & 7.656 & 0.262 & 1.000 & $<0.001$ \\
\hline \multicolumn{8}{|l|}{ Auxin-related } \\
\hline Solyc12g005310 & Auxin responsive $\mathrm{GH} 3$ gene family (GH3-15) & 0.91 & 3.11 & 5.88 & 0.072 & $<0.001$ & $<0.001$ \\
\hline Solyc01g107390 & Auxin responsive $\mathrm{GH} 3$ gene family $(\mathrm{GH} 3-2)$ & 0.11 & -1.97 & 2.63 & 0.819 & $<0.001$ & $<0.001$ \\
\hline Solyc02g064830 & Indole-3-acetic acid-amido synthetase 3-3 & -1.46 & -1.24 & 2.48 & $<0.001$ & $<0.001$ & $<0.001$ \\
\hline Solyc08g068490 & Probable indole-3-acetic acid-amido synthetase GH3.5 & 1.26 & 1.10 & -0.93 & $<0.001$ & $<0.001$ & 0.008 \\
\hline Solyc05g006220 & IAA-amino acid hydrolase & 0.06 & -1.26 & 0.55 & 0.801 & $<0.001$ & $<0.001$ \\
\hline Solyc06g073060 & IAA-amino acid hydrolase 6 & 0.17 & 0.81 & 1.56 & 0.164 & $<0.001$ & $<0.001$ \\
\hline Solyc10g079640 & IAA-amino acid hydrolase 9 & 0.03 & 1.31 & 2.04 & 0.909 & $<0.001$ & $<0.001$ \\
\hline Solyc01g096340 & SAUR family protein (SAUR2) & -0.24 & 1.38 & 0.61 & 0.029034 & $<0.001$ & $<0.001$ \\
\hline Solyc01g110560 & SAUR3 & 0.61 & 0.95 & 1.12 & 0.064 & 0.001 & $<0.001$ \\
\hline Solyc02g062230 & SAUR32 & -0.33 & -0.81 & 1.78 & 0.520 & 0.117 & $<0.001$ \\
\hline Solyc07g042490 & SAUR33 & 0.35 & 0.57 & 1.73 & 0.018 & $<0.001$ & $<0.001$ \\
\hline Solyc03g082510 & SAUR35 & 0.64 & 0.58 & 2.10 & 0.009 & 0.006 & $<0.001$ \\
\hline Solyc03g082520 & SAUR36 & -0.28 & 0.00 & 3.20 & 0.339 & 1.00 & $<0.001$ \\
\hline Solyc03g082530 & SAUR37 & -0.20 & -1.85 & 4.34 & 0.535 & $<0.001$ & $<0.001$ \\
\hline Solyc03g097510 & SAUR38 & 0.00 & -0.68 & 6.59 & 1.000 & 0.483 & $<0.001$ \\
\hline Solyc03g033590 & SAUR50 & 0.25 & -0.88 & 1.58 & 0.262 & 0.0076 & $<0.001$ \\
\hline Solyc04g081270 & SAUR52 & 0.76 & 3.41 & 5.11 & 0.211 & $<0.001$ & $<0.001$ \\
\hline Solyc05g05643 0 & SAUR56 & -0.17 & -0.11 & 2.22 & 0.739 & 0.887 & $<0.001$ \\
\hline Solyc05g056440 & SAUR57 & 0.16 & -0.19 & 2.53 & 0.829 & 0.798 & $<0.001$ \\
\hline Solyc06g07265 0 & SAUR61 & 0.00 & -1.10 & 2.05 & 1.000 & $<0.001$ & $<0.001$ \\
\hline Solyc07g014620 & SAUR63 & 0.00 & 0.16 & 1.56 & 1 & 0.671 & $<0.001$ \\
\hline Solyc09g009980 & SAUR70 & -1.24 & 1.09 & 3.52 & 0.0294 & 0.105 & $<0.001$ \\
\hline Solyc10g018340 & SAUR71 & -1.09 & -3.20 & 2.02 & 0.302 & $<0.001$ & $<0.001$ \\
\hline Solyc03g124020 & SAUR72-like & 1.64 & 0.85 & 2.59 & 0.145 & 0.451 & 0.004 \\
\hline Solyc10g052560 & SAUR75 & 0.05 & 0.89 & 2.40 & 0.954 & 0.369 & 0.005 \\
\hline Solyc09g065850.2 & Auxin-responsive protein IAA (IAA3) & -0.16 & -1.30 & -3.11 & 0.003 & $<0.001$ & $<0.001$ \\
\hline Solyc06g053840 & IAA4 & 0.32 & 0.16 & -2.31 & 0.002 & 0.100 & $<0.001$ \\
\hline Solyc06g053830 & IAA7 & 0.07 & -0.46 & -2.71 & 0.533 & $<0.001$ & $<0.001$ \\
\hline
\end{tabular}


Table 1 continued

\begin{tabular}{|c|c|c|c|c|c|c|c|}
\hline \multirow[t]{2}{*}{ Gene ID } & \multirow[t]{2}{*}{ Annotation } & \multicolumn{3}{|c|}{ Fold change $(\log 2)$} & \multicolumn{3}{|l|}{$p$-value } \\
\hline & & $0 \mathrm{~d}$ & $25 d$ & $\mathrm{Br}$ & $0 \mathrm{~d}$ & $25 d$ & $\mathrm{Br}$ \\
\hline Solyc06g008590 & IAA10 & 1.21 & 0.51 & 1.09 & $<0.001$ & 0.061 & 0.035 \\
\hline Solyc12g096980 & IAA11 & 1.50 & -0.39 & -1.40 & 0.003 & 0.260 & 0.029 \\
\hline Solyc09g064530 & |AA12 & 0.78 & -0.02 & -1.61 & $<0.001$ & 0.937 & $<0.001$ \\
\hline Solyc04g076850.2 & IAA9 & 0.41 & 0.29 & -1.25 & $<0.001$ & $<0.001$ & $<0.001$ \\
\hline Solyc01g097290 & IAA16 & 0.17 & 0.45 & -3.62 & $<0.001$ & $<0.001$ & $<0.001$ \\
\hline Solyc08g021820 & |AA21 & -0.24 & -0.48 & -2.30 & 0.425 & $<0.001$ & $<0.001$ \\
\hline Solyc06g008580 & IAA22 & 0.36 & -1.61 & -4.19 & 0.119 & $<0.001$ & $<0.001$ \\
\hline Solyc09g083280.2 & IAA23 & 0.29 & -1.52 & -2.09 & 0.007 & $<0.001$ & $<0.001$ \\
\hline Solyc09g083290 & IAA24 & -0.11 & -0.94 & -4.60 & 0.619 & $<0.001$ & $<0.001$ \\
\hline Solyc09g090910 & IAA 25 & 0.85 & -0.58 & -2.81 & $<0.001$ & $<0.001$ & $<0.001$ \\
\hline Solyc07g019450 & IAA33 & -0.60 & 2.82 & 5.20 & 0.674 & 0.003 & $<0.001$ \\
\hline Solyc06g066020 & IAA 36 & 1.78 & 0.09 & -3.95 & $<0.001$ & 0.717 & $<0.001$ \\
\hline Solyc05g047460 & Auxin Response Factor 7B & -0.66 & -0.55 & -1.23 & $<0.001$ & $<0.001$ & $<0.001$ \\
\hline Solyc08g082630 & Auxin Response Factor 9A & 1.23 & 1.21 & -1.32 & 0.002 & $<0.001$ & 0.041151 \\
\hline Solyc07g042260 & Auxin response factor (ARF19) & -1.02 & 0.12 & -0.20 & $<0.001$ & 0.120 & 0.017 \\
\hline Solyc1 1g013310 & Auxin transporter-like protein 3 (LAX3) & -0.25 & -1.53 & -0.34 & $<0.001$ & $<0.001$ & $<0.001$ \\
\hline Solyc01g111310 & Auxin transporter-like protein 3 (LAX2) & 0.70 & 0.30 & -1.51 & $<0.001$ & $<0.001$ & $<0.001$ \\
\hline Solyc03g118740 & SIPIN1 & 0.64 & 0.37 & -3.08 & $<0.001$ & $<0.001$ & $<0.001$ \\
\hline Solyc02g037550 & SIPIN-LIKES 3 & 0.25 & -0.38 & -2.79 & $<0.001$ & $<0.001$ & $<0.001$ \\
\hline Solyc01g068410 & SIPIN5 & 1.05 & -0.20 & -2.60 & 0.010 & 0.702 & $<0.001$ \\
\hline Solyc06g059730 & SIPIN6 & 0.54 & 0.65 & -2.04 & 0.146 & 0.123 & $<0.001$ \\
\hline Solyc10g080880 & SIPIN7 & 0.31 & 0.51 & -2.08 & 0.044 & $<0.001$ & $<0.001$ \\
\hline \multicolumn{8}{|c|}{ Cell wall hydrolysis/modification } \\
\hline Solyc09g091430 & Probable pectate lyase 8 & 0.08 & 1.54 & 6.90 & 0.278 & $<0.001$ & $<0.001$ \\
\hline Solyc02g075620 & Probable pectinesterase 53 & 0.844 & 1.765 & 5.319 & $<0.001$ & $<0.001$ & $<0.001$ \\
\hline Solyc07g064190 & Pectinesterase 3 & -1.078 & 0.625 & 4.501 & $<0.001$ & 0.689 & $<0.001$ \\
\hline Solyc07g064180 & Pectin esterase (PME2.1) & 1.455 & 2.704 & 4.271 & $<0.001$ & $<0.001$ & $<0.001$ \\
\hline Solyc01g102350 & Pectin acetylesterase 12 & 0.341 & 1.052 & 3.584 & $<0.001$ & $<0.001$ & $<0.001$ \\
\hline Solyc11g005770 & Pectinesterase & -0.39 & 0.18 & 1.98 & $<0.001$ & 0.035 & $<0.001$ \\
\hline Solyc02g067630 & Polygalacturonase 1 & -1.59 & 1.60 & 12.41 & 0.153 & 0.130 & $<0.001$ \\
\hline Solyc02g067640 & Polygalacturonase 2 & -1.22 & 0.04 & 11.55 & 0.338 & 1.000 & $<0.001$ \\
\hline Solyc12g019230 & Polygalacturonase-like & -2.55 & -0.44 & 7.50 & 0.001 & 0.778 & 0.000 \\
\hline Solyc04g015530 & Dehiscence polygalacturonase & -1.91 & -0.17 & 7.33 & $<0.001$ & 0.895 & $<0.001$ \\
\hline Solyc08g081480 & Polygalacturonase-like protein & 0.381 & 1.193 & 3.706 & $<0.001$ & $<0.001$ & $<0.001$ \\
\hline Solyc02g080210 & Polygalacturonase-2a & -0.32 & 2.29 & 2.24 & 0.800 & $<0.001$ & $<0.001$ \\
\hline Solyc12g096750 & Polygalacturonase 4 & -1.68 & 1.51 & 5.85 & $<0.001$ & $<0.001$ & $<0.001$ \\
\hline Solyc12g096740 & Polygalacturonase 5 & -4.05 & -1.6 & 8.57 & $<0.001$ & $<0.001$ & $<0.001$ \\
\hline Solyc12g019180 & Polygalacturonase 7 & -0.49 & 1.24 & 6.8 & 0.758 & 0.170 & $<0.001$ \\
\hline
\end{tabular}


Table 1 continued

\begin{tabular}{|c|c|c|c|c|c|c|c|}
\hline \multirow[t]{2}{*}{ Gene ID } & \multirow[t]{2}{*}{ Annotation } & \multicolumn{3}{|c|}{ Fold change $(\log 2)$} & \multicolumn{3}{|l|}{$p$-value } \\
\hline & & $0 \mathrm{~d}$ & $25 d$ & $\mathrm{Br}$ & $0 \mathrm{~d}$ & $25 d$ & $\mathrm{Br}$ \\
\hline Solyc01g094970 & Polygalacturonase family protein & -2.75 & -2.40 & 4.41 & $<0.001$ & $<0.001$ & $<0.001$ \\
\hline Solyc03g006700 & Peroxidase & -2.19 & 1.06 & 3.87 & $<0.001$ & $<0.001$ & $<0.001$ \\
\hline Solyc08g081620 & Endo-1,4-beta-glucanase precursor (Cel1) & 0.23 & 1.50 & 5.38 & $<0.001$ & $<0.001$ & $<0.001$ \\
\hline Solyc09g010210 & Endo-1,4-beta-glucanase precursor (Cel2) & 0.38 & 0.50 & 4.91 & $<0.001$ & $<0.001$ & $<0.001$ \\
\hline Solyc09g075360 & Endo-1,4-beta-glucanase precursor (Cel4) & -0.29 & 0.84 & 2.67 & $<0.001$ & $<0.001$ & $<0.001$ \\
\hline Solyc11g040340 & Endo-1,4-beta-glucanase precursor (Cel7) & 0.85 & -0.25 & 2.07 & $<0.001$ & $<0.001$ & $<0.001$ \\
\hline Solyc08g082250 & Endo-1,4-beta-glucanase precursor (Cel8) & -0.05 & 0.18 & 2.00 & 0.238 & $<0.001$ & $<0.001$ \\
\hline Solyc07g009380 & Xyloglucan endotransglycosylase (XTH2) & 1.17 & 5.17 & 6.05 & $<0.001$ & $<0.001$ & $<0.001$ \\
\hline Solyc03g093110 & Xyloglucan endotransglycosylase (XTH3) & 0.64 & 0.30 & 1.42 & $<0.001$ & 0.170 & $<0.001$ \\
\hline Solyc03g093120 & Xyloglucan endotransglycosylase (XTH3) & 0.20 & 0.01 & 3.06 & 0.24 & 0.990 & $<0.001$ \\
\hline Solyc03g093130 & Xyloglucan endotransglycosylase (XTH3) & 0.00 & 0.52 & 1.73 & 1.000 & 0.062 & $<0.001$ \\
\hline Solyc11g065600 & Xyloglucan endotransglycosylase (XTH4) & 1.21 & 1.10 & 1.52 & $<0.001$ & $<0.001$ & $<0.001$ \\
\hline Solyc01g091920 & Xyloglucan endotransglycosylase (XTH7) & 0.87 & 2.85 & 1.98 & $<0.001$ & $<0.001$ & $<0.001$ \\
\hline Solyc12g011030 & Xyloglucan endotransglycosylase (XTH9) & 0.73 & 0.19 & 4.89 & $<0.001$ & 0.420 & $<0.001$ \\
\hline Solyc07g056000 & Xyloglucan endotransglycosylase (XTH10) & -0.49 & -0.56 & 2.90 & $<0.001$ & $<0.001$ & $<0.001$ \\
\hline Solyc12g017240 & Xyloglucan endotransglycosylase (XTH11) & -0.10 & 0.33 & 1.00 & 0.29 & 0.001 & $<0.001$ \\
\hline Solyc07g052980 & Xyloglucan endotransglycosylase (XTH16) & 0.51 & 1.27 & 0.46 & $<0.001$ & $<0.001$ & $<0.001$ \\
\hline Solyc01g112000 & Expansin-like protein precursor 1 (EXLA1) & -0.18 & -0.62 & 2.69 & 0.034 & $<0.001$ & $<0.001$ \\
\hline Solyc10g086520 & Expansin (EXPA6) & 1.09 & 0.76 & 4.06 & 0.006 & 0.130 & $<0.001$ \\
\hline Solyc06g005560 & Expansin 9 (EXPA9) & 0.64 & 0.52 & 2.84 & $<0.001$ & $<0.001$ & $<0.001$ \\
\hline Solyc06g076220 & Expansin18 (EXPA18) & 0.63 & 0.41 & 2.71 & $<0.001$ & $<0.001$ & $<0.001$ \\
\hline Solyc08g077910 & Expansin 45 (EXPA45) & -0.852 & 0.041 & 9.25 & 0.540 & 0.995 & $<0.001$ \\
\hline Solyc06g051800 & Fruit ripening regulated expansin1 (EXP1) & 0.69 & -0.01 & 4.01 & $<0.001$ & 0.955 & $<0.001$ \\
\hline Solyc06g049050 & Expansin (EXP2) & 0.85 & 2.06 & 2.06 & $<0.001$ & $<0.001$ & $<0.001$ \\
\hline Solyc04g081870 & Expansin precursor (EXP11) & 0.42 & 0.87 & 4.64 & $<0.001$ & $<0.001$ & $<0.001$ \\
\hline Solyc01g090810 & Beta-expansin precursor(EXPB1) & -0.26 & -2.84 & 9.59 & 0.847 & $<0.001$ & $<0.001$ \\
\hline Solyc05g007830 & Alpha-expansin 1 precursor & 1.15 & 0.17 & 0.41 & $<0.001$ & 0.004 & $<0.001$ \\
\hline
\end{tabular}

\section{Silencing SIBL4 affected the auxin level in AZ}

Auxin plays critical role in the maintenance of fruit attachment to plants ${ }^{3}$. There were 103 auxin-related DEGs in the SlBL4 RNAi line compared with the WT plant at the pre-abscission AZs. This included auxinresponsive genes, such as $A u x / I A A$, Gretchen Hagen 3 (GH3), small auxin upregulated RNA (SAUR), and auxin response factor $(A R F s)$, and auxin transport-related genes, such as PIN (pin-formed protein) and like auxin (LAX) (Table 1).

For instance, $A R F 7 B$ (Solyc05g047460), ARF9A (Solyc08g082630), and ARF19 (Solyc07g042260) were downregulated by 1.23-, 1.32-, and 0.2-fold, respectively, in the SIBL4 RNAi line compared with the WT plant at the abscission stage. LAX2 (Solyc01g111310) and LAX3 (Solyc11g013310) were downregulated by 0.34 - and 1.51fold, respectively, in the SIBL4 RNAi line compared with the WT plant at the abscission stage. SIPIN1 (Solyc03g118740), SlPIN-likes 3 (Solyc02g037550), SIPIN5 (Solyc01g068410), SIPIN6 (Solyc06g059730), and SIPIN7 (Solyc10g080880) were downregulated by 3.08-, 2.79-, 2.60-, 2.04-, and 2.08-fold, respectively, in the SIBL4 RNAi line compared with the WT plant at the abscission stage (Table 1). The promoter sequences were also analyzed in LAX3 and SIPIN1, which revealed the SlBL4 binding (G/A) GCCCA (A/T/C) motif. Transient dual-luciferase 


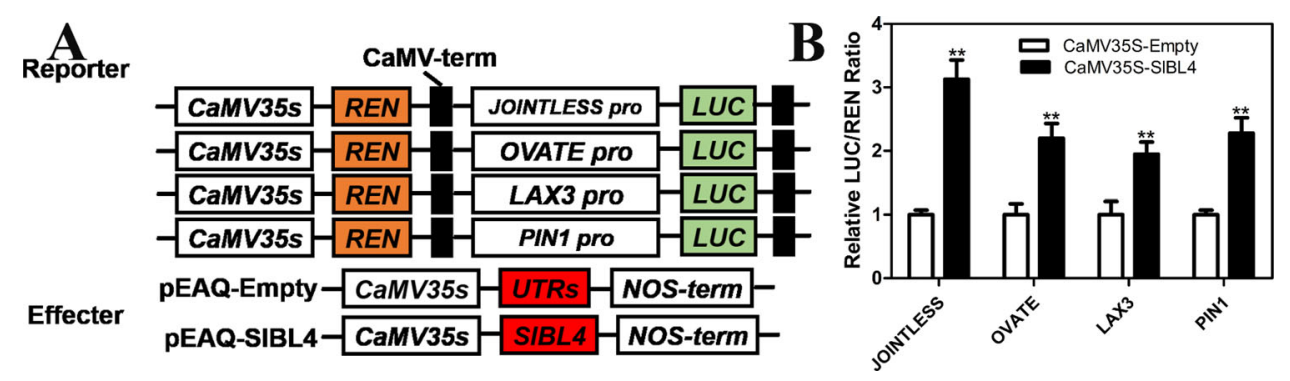

Fig. 6 SIBL4 directly activates the expression of genes related to fruit pedicel development. A Diagram of the reporter and effector constructs used in the transient dual-luciferase assays in leaves of tobacco seedlings; LUC, firefly luciferase; REN, Renilla luciferase. B In vivo interactions of SIBL4 with the promoters obtained from the JOINTLESS, OVATE, LAX3 or PIN1 transient assays in tobacco leaves. The data are presented as the means ( \pm SE), $n=6$. Significant differences compared with the WT were determined by Student's $t$-test: ${ }^{* *} P<0.01$
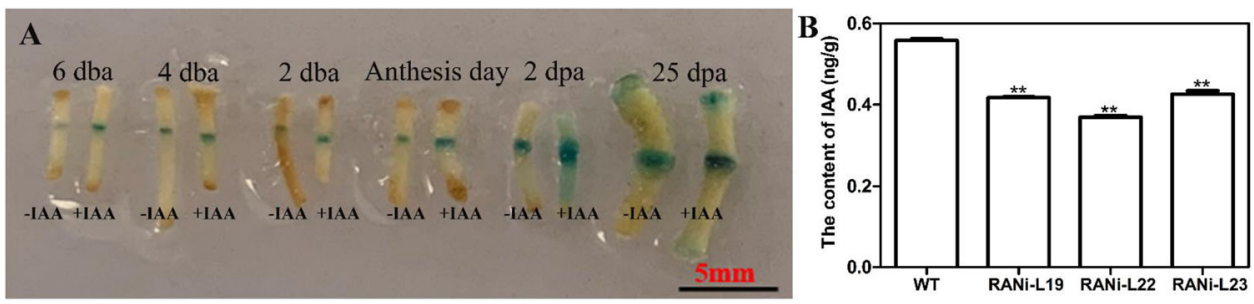

Fig. 7 Effects of IAA treatment on the floral pedicel abscission zone of SIBL4pro::GUS plants and auxin concentrations in pedicel AZs. A Effects of exogenous auxin (+IAA) and control treatment (-IAA) on the floral pedicel abscission zones of SIBL4pro::GUS plants; $6 \mathrm{dba}, 4 \mathrm{dba}, 2 \mathrm{dba}$, anthesis day, $2 \mathrm{dpa}, 25 \mathrm{dpa}$; dba: day before anthesis; dpa: day post anthesis. B The content of IAA; standard errors are indicated by vertical bars. The asterisks indicate significant differences at $P<0.01\left(^{* *}\right)$ as determined by the $t$-test; WT wild type, RNAi-L19, RNAi-L22, RNAi-L23 three different lines of SIBL4 RNAi plants

assays showed that overexpression of SlBL4 significantly increased the luciferase activity driven by the promoters of LAX3 and SIPIN1 compared with that of the empty control (Fig. 6A, B), indicating that SlBL4 activated the transcription of LAX3 and SIPIN1.

To analyze the effect of IAA on the floral pedicel AZ of SIBL4pro::GUS plants, the flower was removed and replaced by $1 / 2$ MS medium containing $50 \mu \mathrm{g} / \mathrm{g}$ IAA for $24 \mathrm{~h}$, which accelerated GUS expression in the pedicel AZ compared with that in the control (-IAA) (Fig. 7A). In addition, we examined the IAA concentrations in tomato pedicel AZs by acquisition ultraperformance liquid chromatography. The IAA concentrations in the AZs of SlBL4 RNAi plants were lower than those in the AZs of WT plants (Fig. 7). The expression of ARF9A and SIPIN7 was determined by qRT-PCR, and the results coincided with the RNA-seq results (Fig. S4). In conclusion, silencing SlBL4 influenced the auxin efflux, signaling, and content in tomato pedicels.

\section{Suppression of SIBL4 induces the expression of genes encoding cell wall hydrolytic enzymes}

The expression of genes encoding cell wall degrading and remodeling enzymes, including pectinases (PG, PL), cellulase (Cel), xyloglucan endotransglucosylase-hydrolase $(\mathrm{XTH})$, and expansin (EXP), was reported to be induced in response to the abscission stimulus. Our transcriptome analyses showed that many of the genes mentioned above were expressed at higher levels in the SIBL4 RNAi line than in the WT plant at the abscission stage. Among the DEGs, $16 P G / P L$ genes, $5 \mathrm{Cel}$ genes, $10 \mathrm{XTH}$ genes, 10 EXP genes, and 1 peroxidase $(P O D)$ gene were found (Table 1). For instance, PG1 (Solyc02g067630), PG2 (Solyc02g067640), and PE (Solyc11g005770) were upregulated by 12.41-, 11.55-, and 1.98-fold, respectively. Cel1 (Solyc08g081620) was upregulated by 5.38 -fold. XTH2 (Solyc07g009380) was upregulated by 6.05 -fold. EXPA45 (Solyc08g077910) and EXPB1 (Solyc01g090810) were upregulated by 9.25- and 9.59-fold, respectively. These genes were vital for cell wall remodeling and middle lamella degradation at the late stages of the abscission process. The expression levels of PG1, PE, XTH2, and EXPA45 were evaluated by $\mathrm{RT}-\mathrm{qPCR}$, and the results coincided with the RNA-seq results (Fig. S4).

\section{Discussion}

BELL TFs play various roles in plant morphology and fruit development ${ }^{29,37,38}$, whereas they are seldom 
reported to be involved in fruit pedicel organogenesis and abscission. Here, we reported that SlBL4 is an important regulator of fruit pedicel organogenesis and abscission in tomatoes.

\section{SIBL4 regulated WUS, BI, CUP, OVATE, and Ls in the regulation of competency to respond to abscission- promoting signaling}

Abscission can occur at four key steps, namely, differentiation of the AZ, acquisition of the competence to respond to abscission signals, activation of organ abscission, and formation of a protective layer on the main body side of the $A Z^{6,7,39}$. We elucidated the role of SIBL4 in abscission by observing the SlBL4 RNAi fruits at $25 \mathrm{dpa}$. Our anatomic analysis of the floral pedicel AZ showed greater enlargement of the epidermal cells and disappearance of the small cells at the separation zone in the SlBL4 RNAi plant pedicel compared with the control (Fig. 3). These results suggested that the size and proliferation of the AZ cells are likely to be activated due to the repression of SlBL4 expression. The involvement of TF genes, such as WUS, Bl, CUP, JOINTLESS, OVATE, LBD1, and $L s$, was evident in the anthesis pedicel $\mathrm{AZs}^{14,40-42}$. Moreover, our analyses also revealed AZ-specific downregulation of WUS, CUP, JOINTLESS, and OVATE and upregulation of $B l, M Y B 78$, and $L B D 1$ in the SlBL4 RNAi line compared with the WT plant at the abscission stage (Table 1). WUS, OVATE, and CUP function coordinate to maintain cells in an undifferentiated state and to maintain a small cell size, which are critical for meristem activities $^{7,40,42,43}$. Therefore, the reduced expression of WUS, CUP, JOINTLESS, and OVATE caused by an abscission signal may have resulted in enlargement of the separation zone cells for the onset of abscission in the RNAi line compared with the WT plant. Our results indicated that SlBL4 directly activated JOINTLESS and OVATE expression, thus accounting for the disappearance of the small cells at the separation zone in the SlBL4 RNAi plant pedicel (Fig. 6). The $B l$ gene, which encodes the R2R3 class MYB TF, controls lateral meristem development ${ }^{17,44}$ and is upregulated in the AZ-formation stage in tomato ${ }^{14}$. In combination with the SlBL4 expression pattern in AZs, this finding explains why SlBL4 contributes to the maintenance of the undifferentiated status of cell proliferation and differentiation of flower pedicel AZs by affecting the expression of meristem activity genes.

\section{SIBL4 regulates the auxin gradient in the pedicel and affects the expression of auxin transport-related genes}

Several studies have found that auxin plays a critical role in pedicel abscission via continuous flow from flowers or fruit $^{3,8,10,43}$. Our results demonstrated that silencing SlBL4 affects the formation of pedicels in tomato plants. The IAA content in the RNAi lines was less than that in the WT plants (Fig. 7B). Furthermore, IAA treatments were performed on the seeding and floral pedicel AZs to show their effects on the abscission process. The results showed that the explants began to abscise at $8 \mathrm{~h}$ in the RNAi lines not treated with IAA (Fig. 2D), but they began to abscise at $24 \mathrm{~h}$ in the RNAi lines treated with IAA. Compared with this, the explants began to abscise at $16 \mathrm{~h}$ in the WT plants not treated with IAA (Fig. 2E). The root growth phenotype also indicated that the RNAi lines were more sensitive to IAA treatment than the WT plants (Fig. 2J and K). All of the above results demonstrated that IAA could postpone AZ abscission and that knockdown of SIBL4 could cause an early abscission phenotype by reducing the accumulation of IAA. At the break stage, the fruit began to drop, and the auxin contents were reduced in the AZs of the SlBL4 RNAi lines compared with the WT plants, suggesting that SlBL4 plays a role in modulating auxin levels (Figs. 4 and 7). The effect of IAArelated gene expression can also help clarify which genes are likely to directly or indirectly participate in the abscission process. SIPIN1 plays an important role in regulating not only the basipetal auxin flux from the seed to the plant but also the fruit to the basal organ ${ }^{3,45-47}$. Silencing the expression of SIPIN1 decreases the auxin content in the AZ, which is necessary for preventing tomato pedicel abscission ${ }^{46}$. In $A$. thaliana, LAX3 has been shown to actively regulate auxin influx ${ }^{48,49}$. LAX3, which is an ortholog of $A t L A X 3$, plays a role in the regulation of auxin influx in the tomato pericarp ${ }^{47}$. SIPIN1 and LAX3 were downregulated by 3.08- and 0.34-fold, respectively, in the SlBL4 RNAi line compared with the WT plant at the abscission stage (Table 1). Our results also indicated that SlBL4 directly activated the expression of the auxin efflux transporter genes SIPIN1 and LAX3, thus accounting for the lower auxin content in the SlBL4 RNAi plant pedicel (Figs. 6-7). ARF7 and ARF19 are involved in abscission in $A$. thalian ${ }^{50}$, and the expression of SlARF19 is upregulated in flower AZs (FAZs) ${ }^{51}$. The expression level of ARF9 homolog (ARF9A) was shown to be significantly higher in the proximal region than in AZs and distal regions ${ }^{10}$. Our transcriptomic results showed that the transcript abundances of three auxin response genes (ARFs; ARF7B, ARF9A, or ARF19) were downregulated in the RNAi line compared with the WT plant at the abscission stage (Table 1). Constant auxin flux plays an important role in preventing abscission ${ }^{1}$. SIPIN9 and PIN-like 3 were downregulated in the FAZs of KD1 antisense tomato plants, which suggested that the $K D 1$ gene plays a role in manipulating auxin levels by altering the expression of auxin efflux transporters ${ }^{33}$. The SIPIN3, SIPIN5, SIPIN6, and SIPIN7 genes were highly expressed in $\mathrm{FAZs}^{52}$. Five PIN genes (SIPIN1, SIPIN-LIKES 3, SIPIN5, SIPIN6, and SIPIN7) and two LAX genes (LAX2 and $L A X 3)$ were downregulated in the SlBL4 RNAi line 
compared with the WT plant at the abscission stage (Table 1), indicating a complex interplay among different components (AUX/IAA, ARFs, PIN, and LAXs) of the auxin response pathway during tomato pedicel abscission. These results were consistent with our hypothesis that SlBL4 plays a role in manipulating auxin levels in the AZ, perhaps by regulating transport genes for auxin influx and efflux. The timing of pedicel abscission was determined by the auxin level ${ }^{43}$. Therefore, SlBL4 may be involved in the timing of abscission onset by regulating the expression of ARFs, auxin influx, and efflux transport genes.

\section{The SIBL4 gene suppresses cell wall hydrolytic enzymes in tomato pedicles}

The last step of abscission is an activation of cell walldegrading enzymes such as PG, Cel, XTH, and EXP and subsequent removal of plant organs ${ }^{43-61}$. In our study, 8 polygalacturonase, $5 \mathrm{Cel}, 10 \mathrm{XTH}, 10 \mathrm{EXP}$, and 1 peroxidase gene were upregulated in the SlBL4 RNAi line compared with the WT plants at the abscission stage (Table 1). Silencing of PGs delayed abscission in tomato ${ }^{62}$. PG1 was highly expressed in flower AZs, and its expression was inhibited by auxin ${ }^{63,64}$. Cel1 and Cel2 play important roles in tomato flower and leaf abscission ${ }^{53,65}$. In our previous study, we showed that SIPE expression was regulated by SIBL4, that the transcription of SIPE was directly repressed by SlBL4, and that such actions were involved in pectin depolymerization ${ }^{29}$. The expression of SIPE was also increased in the SlBL4 RNAi line compared with the WT plant at the abscission stage, which suggested that SIPE is also involved in cell wall modification and cell separation during pedicel abscission in tomato. Expansins (EXPs) are involved in the cell wall and pectin modification during the abscission process ${ }^{66-70}$. Expansins also reportedly regulate pedicel abscission in $A$. thaliana and soybean (Glycine $\max$ L.) and leaflet abscission in elderberry (Sambucus nigra), tomato, and citrus (Citrus L.) ${ }^{52,60,66,68,71}$. We observed that the expression levels of several EXP genes, such as EXPA45 or EXPB1, were significantly upregulated in the SlBL4 RNAi line compared with the WT plant at the abscission stage.

In conclusion, SlBL4 plays a role in establishing and maintaining the properties of pre-abscission tomato pedicel AZs by regulating shoot meristem genes, auxin influx, and efflux transport genes and cell wall hydrolytic genes. The results of this study provide insight into a new aspect of the regulation of organ development and abscission by BELL family proteins with regard to tomato pedicel formation.

\section{Acknowledgements}

This work was supported by the National Natural Science Foundation of China (31601763 and 31972470) and the Inner Mongolia University High-Level Talent Research Program (12000-15031934).

\begin{abstract}
Author details
'Key Laboratory of Herbage \& Endemic Crop Biotechnology, Ministry of Education, School of Life Science, Inner Mongolia University, Hohhot 010021, China. ${ }^{2}$ Key Laboratory of Plant Hormones and Development Regulation of Chongqing, School of Life Sciences, Chongqing University, 401331 Chongqing, China. ${ }^{3}$ School of Biology and Basic Medical Sciences, Soochow University, Suzhou, China. ${ }^{4}$ Center of Plant Functional Genomics, Institute of Advanced Interdisciplinary Studies, Chongqing University, 401331 Chongqing, China
\end{abstract}

\section{Author contributions}

F.Y. performed most of the experiments and wrote the manuscript. Z.H.G., J.G.H., and Z.Q. helped to perform the dual-luciferase transient expression assays and analyze the data. X.S.M., R.N.Y., and R.Y.B. cultivated the tomato plants and performed the qPCR experiments. W.D. revised the manuscript. $H$. W. and Z.G.L. conceived the research and revised the manuscript. All authors read and approved the final manuscript.

\section{Data availability}

The data used to support the findings of this study are available from the corresponding author upon request.

\section{Conflict of interest}

The authors declare no competing interests.

Supplementary information The online version contains supplementary material available at https://doi.org/10.1038/s41438-021-00515-0.

Received: 20 August 2020 Revised: 8 January 2021 Accepted: 6 February 2021

Published online: 01 April 2021

\section{References}

1. Roberts, J. A., Elliott, K. A. \& Gonzalez-Carranza, Z. H. Abscission, dehiscence, and other cell separation processes. Annu. Rev. Plant Biol. 53, 131-158 (2002).

2. Addicot, F. T. Abscission (University of California Press, 1982).

3. Taylor, J. E. \& Whitelaw, C. A. Signals in abscission. N. Phytologist 151, 323-339 (2001).

4. Bleecker, A. B. \& Patterson, S. E. Last exit: senescence, abscission, and meristem arrest in Arabidopsis. Plant Cell 9, 1169-1179 (1997).

5. McManus, M. T. Further examination of abscission zone cells as ethylene target cells in higherplants. Ann. Bot. 101, 285-292 (2008).

6. Meir, S. et al. Identification of defense-related genes newly-associated with tomato flower abscission. Plant SignaBehavior 6, 590-593 (2011).

7. Wang, X. et al. Transcriptome analysis of tomato flower pedicel tissues reveal abscission zone-specific modulation of key meristem activity genes. PLOS ONE 8, e55238 (2013).

8. Roberts, J. A., Elliott, K. A. \& Gonzalez-Carranza, Z. H. Abscission, dehiscence, andother cell separation processes. Annu. Rev. Plant Biol. 53, 131-158 (2002).

9. Estornell, L. H., Agustí, J., Merelo, P., Talón, M. \& Tadeo, F. R. Elucidating mechanisms underlying organ abscission. Plant Sci. 199-200, 48-60 (2013).

10. Nakano, T., Fujisawa, M., Shima, Y. \& Ito, Y. Expression profiling of tomato pre-abscission pedicels provides insights into abscission zone properties including competence to respond to abscission signals. BMC Plant Biol. 13, 1-19 (2013).

11. Lashbrook, C. C., Tieman, D. M. \& Klee, H. J. Differential regulation of the tomato ETR gene family throughout plant development. Plant J. 15, 243-252 (1998).

12. Mao, L. et al. JOINTLESS is a MADS-box gene controlling tomato flower abscission zone development. Nature 406, 910-913 (2000).

13. Budiman, M. A. et al. Localization of jointless-2 gene in the centromeric region of tomato chromosome 12 based on high resolution genetic and physical mapping. Theor. Appl. Genet. 108, 190-196 (2004).

14. Nakano, T. et al. MACROCALYX and JOINTLESS interact in the transcriptional regulation of tomato fruit abscission zone development. Plant Physiol. 158, 439-450 (2012). 
15. Liu, D. et al. The sepallata mads-box protein slmbp21 forms protein complexes with jointless and macrocalyx as a transcription activator for development of the tomato flower abscission zone. Plant J. 77, 284-296 (2014).

16. Szymkowiak, E. J. \& Irish, E. E. JOINTLESS suppresses sympodial identity in inflorescence meristems of tomato. Planta 223, 646-658 (2006).

17. Quinet, M., Kinet, J. M. \& Lutts, S. Flowering response of the uniflora: blind:selfpruning and jointless: uniflora: self-pruning tomato (Solanum lycopersicum) triple mutants. Physiologia Plant. 141, 166-176 (2011).

18. Schumacher, K., Schmitt, T., Rossberg, M., Schmitz, G. \& Theres, K. The Lateral suppressor ( $L S$ ) gene of tomato encodes a new member of the $\mathrm{VHIID}$ protein family. Proc. Natl Acad. Sci. USA 96, 290-295 (1999).

19. Mc Kim, S. M. et al. The BLADE-ON-PETIOLE genes are essential for abscission zone formation in Arabidopsis. Development 135, 1537-1546 (2008).

20. Bürglin, T. R. Analysis of TALE superclass homeobox genes (MEIS, PBC, KNOX, Iroquois, TGIF) reveals a novel domain conserved between plants and animals. Nucleic Acids Res. 25, 4173-4180 (1997).

21. Douglas, S. J., Chuck, G., Dengler, R. E., Pelecanda, L. \& Riggs, C. D. KNAT1 and ERECTA regulate inflorescence architecture in Arabidopsis. Plant Cell 14, 547-558 (2002)

22. Venglat, S. P. et al. The homeobox gene BREVIPEDICELLUS is a key regulator of inflorescence architecture in Arabidopsis. Proc. Natl Acad. Sci. USA 99, 4730-4735 (2002).

23. Ragni, L., Belles-Boix, E., Gunl, M. \& Pautot, V. Interaction of KNAT6 and KNAT2 with BREVIPEDICELLUS and PENNYWISE in Arabidopsis inflorescences. Plant Cell 20, 888-900 (2008).

24. Li, Y., Pi, L., Huang, H. \& Xu, L. ATH1 and KNAT2 proteins act together in regulation of plant inflorescence architecture. J. Exp. Bot. 63, 1423-1433 (2012).

25. Byrne, M. E. Phyllotactic pattern and stem cell fate are determined by the Arabidopsis homeobox gene BELLRINGER. Development 130, 3941 (2003).

26. Smith, H. M. \& Hake, S. The interaction of two homeobox genes, BREVIPEDICELLUS and PENNYWISE, regulates internode patterning in the Arabidopsis inflorescence. Plant Cell 15, 1717-1727 (2003).

27. Smith, H. M., Campbell, B. C. \& Hake, S. Competence to re spond to floral inductive signals requires the homeobox genes PENNYWISE and POUNDFOOLISH. Curr. Biol. 14, 812-817 (2004).

28. Bhatt, A. M., Etchells, J. P., Canales, C., Lagodienko, A. \& Dick inson, H. VAAMANA-a BEL1-like homeodomain protein, interacts with KNOX proteins $\mathrm{BP}$ and STM and regulates inflorescence stem growth in Arabidopsis. Gene 328, 103-111 (2004).

29. Yan, F. et al. SIBL4 regulates chlorophyll accumulation, chloroplast development and cell wall metabolism in tomato fruit. J. Exp. Bot. 71, 5549-5561 (2020).

30. Deng, W. et al. The tomato SIIAA15 is involved in trichome formation and axillary shoot development. N. Phytologist 194, 379-390 (2012).

31. Fillatti, J. J., Kiser, J., Rose, R. \& Comai, L. Efficient transfer of aglyphosate tolerance gene into tomato using a binary Agrobacterium tumefaciens vector. Nat. Biotechnol. 5, 726-730 (1987).

32. Yan, Fang et al. Ectopic expression a tomato KNOX Gene Tkn4 affects the formation and the differentiation of meristems and vasculature. Plant Mol. Biol. 89, 589-605 (2015).

33. $\mathrm{Ma}$, C. et al. A knotted1-like homeobox protein regulates abscission in tomato by modulating the auxin pathway. Plant Physiol. 167, 844-853 (2015).

34. Barny, C. S. et al. Altered chloroplast development and delayed fruit ripening caused by mutations in a zinc metalloprotease at the lutescent2 locus of tomato. Plant Physiol. 159, 1086-1098 (2012).

35. Hellens, R. P. et al. Transient expression vectors for functional genomics, quantification of promoter activity and RNA silencing in plants. Plant Methods 1, 13 (2005)

36. Sexton, R. \& Roberts, J. A. Cell biology of abscission. Annu. Rev. Plant Biol. 33 133-162 (1982).

37. Hay, A. \& Tsiantis, M. KNOX genes: versatile regulators of plant development and diversity. Development 137, 3153-3165 (2010).

38. Lanhuan, Meng et al. 2018. BEL1-LIKE HOMEODOMAIN 11 regulates chloroplast development and chlorophyll synthesis in tomato fruit. Plant J. 94 1126-1140 (2018).

39. Patterson, S. E. Cutting loose Abscission and dehiscence in Arabidopsis. Plant Physiol. 126, 494-500 (2001)

40. Mayer, K. F. et al. Role of WUSCHEL in regulating stem cell fate in the Arabidopsis shoot meristem. Cell 95, 805-815 (1998).
41. Muller, D., Schmitz, G. \& Theres, K. Blind homologous R2R3 Myb genes control the pattern of lateral meristem initiation in Arabidopsis. Plant Cell 18, 586-597 (2006).

42. Raman, S. et al. Interplay of miR164, CUP-SHAPED COTYLEDON genes and LATERAL SUPPRESSOR controls axillary meristem formation in Arabidopsis thaliana. Plant J. 55, 65-76 (2008).

43. Meir, S. et al. Microarray analysis of the abscission-related transcriptome in the tomato flower abscission zone in response to auxin depletion. Plant Physiol. 154, 1929-1956 (2010).

44. Schmitz, G. et al. The tomato Blind gene encodes a MYB transcription factor that controls the formation of lateral meristems. Proc. Natl Acad. Sci. USA 99, 1064-1069 (2002)

45. Manojit, M. B. et al. The manipulation of auxin in the abscission zone cells of Arabidopsis flowers reveals that indoleacetic acid signaling is a prerequisite for organ shedding. Plant Physiol. 162, 96-106 (2013).

46. Shi, Z. et al. SIPIN1 regulates auxin efflux to affect flower abscission process. Sci. Rep. 7, 14919 (2017)

47. Pattison, R. J. \& Carmen, C. Evaluating auxin distribution in tomato (Solanum lycopersicum) through an analysis of the PIN and AUXLAX gene families. Plant J. 70, 4 (2012).

48. Swarup, $K$. et al. The auxin influx carrier LAX3 promotes lateral root emergence. Nat. Cell Biol. 10, 946-954 (2008).

49. Vandenbussche, F. et al. The auxin influx carriers AUX1 and LAX3 are involved in auxin-ethylene interactions during apical hook development in Arabidopsis thaliana seedlings. Development 137, 597-606 (2010).

50. Ellis, C. M. et al. Auxin Response Factor1 and Auxin Response Factor 2 regulate senescence and floral organ abscission in Arabidopsis thaliana. Development 132, 4563-4574 (2005).

51. Guan, X. et al. Temporal and spatial distribution of auxin response factor genes during tomato flower abscission. J. Plant Growth Regul. 33, 317-327 (2014).

52. Srivignesh, S. et al. (2016). De novo transcriptome sequencing and development of abscission zone-specific microarray as a new molecular tool for analysis of tomato organ abscission. Front. Plant Sci. 6, 1258 (2016).

53. Lashbrook, C. C., Gonzalez-Bosch, C. \& Bennett, A. B. Two divergent indo-b-1,4glucanase genes exhibit overlapping expression in ripening fruit and abscising flowers. Plant Cell 6, 1485-1493 (1994).

54. Kalaitzis, P., Solomos, T. \& Tucker, M. L. Three different polygalacturonases are expressed in tomato leaf and flower abscission, each with a different temporal expression pattern. Plant Physiol. 113, 1303-1308 (1997).

55. Lashbrook, C. C., Giovannoni, J. J., Hall, B. D., Fisher, R. L. \& Bennett, A. B. Transgenic analysis of tomato endo-b-1,4-glucanase gene function: role of Cel1 in floral abscission. Plant J. 13, 303-310 (1998).

56. Agusti', J., Merelo, P., Cerco's, M., Tadeo, F. R. \& Talo'n, M. Ethylene-induced differential gene expression during abscission of citrus leaves. J. Exp. Bot. 59, 2717-2733 (2008).

57. Agusti', J. et al. Comparative transcriptional survey between lasermicrodissected cells from laminar abscission zone and petiolar cortical tissue during ethylene-promoted abscission in citrus leaves. BMC Plant Biol. 9 127 (2009).

58. Roberts, J. A. \& Gonzalez-Carranza, Z. H. Pectinase function in abscission. Stewart Postharvest Rev. 5, 1-4 (2009)

59. Kim, J. Four shades of detachment: regulation of floral organ abscission. Plant Signal Behav. 9, e976154 (2014).

60. Merelo, Paz et al. Cell wall remodeling in abscission zone cells during ethylene-promoted fruit abscission in citrus. Front. Plant Sci. 8, 126 (2017).

61. Song, L., Valliyodan, B., Prince, S., Wan, J. \& Nguyen, H. Characterization of the XTH gene family: new insight to the roles in soybean flooding tolerance. Int. J. Mol. Sci. 19, 2705 (2018).

62. Jiang, C. Z., Lu, F., Imsabai, W., Meir, S. \& Reid, M. S. Silencing polygalacturonase expression inhibits tomato petiole abscission. J. Exp. Bot 59, 973-979 (2008).

63. Kalaitzis, P., Koehler, S. M. \& Tucker, M. L. Cloning of a tomato polygalacturonase expressed in abscission. Plant Mol. Biol. 28, 647-656 (1995).

64. Hong, S. B., Sexton, R. \& Tucker, M. L. Analysis of gene promoters for two tomato polygalacturonases expressed in abscission zones and the stigma. Plant Physiol. 123, 869-881 (2000). 
65. Brummell, D. A., Hall, B. D. \& Bennett, A. B. Antisense suppression of tomato endo-1,4-beta-glucanase Cel2 mRNA accumulation increases the force required to break fruit abscission zones but does not affect fruit softening. Plant Mol. Biol. 40, 615-622 (1999).

66. Cho, H.-T. \& Cosgrove, D. J. Altered expression of expansin modulates leaf growth and pedicel abscission in Arabidopsis thaliana. Proc. Natl Acad. Sci. USA 97, 9783-9788 (2000).

67. Lee, Y., Choi, D. \& Kende, H. Expansins: ever-expanding numbers and functions. Curr. Opin. Plant Biol. 4, 527-532 (2001).

68. Cosgrove, D. J. et al. The growing world of expansins. Plant Cell Physiol. 43, 1436-1444 (2002)
69. Belfield, E. J., Ruperti, B., Roberts, J. A. \& McQueen-Mason, S. Changes in expansion activity and gene expression during ethylene-promoted leaflet abscission in Sambucus nigra. J. Exp. Bot. 56, 817-823 (2005).

70. Kim, J. et al. Examination of the abscission-associated transcriptomes for soybean, tomato and Arabidopsis highlights the conserved biosynthesis of an extensible extracellular matrix and boundary layer. Front. Plant Sci. 6, 1109 (2015)

71. Tucker, M. L., Burke, A., Murphy, C. A., Thai, V. K. \& Ehrenfried, M. L Gene expression profiles for cell wall-modifying proteins associated with soybean cyst nematode infection, petiole abscission, root tips, flowers, apical buds, and leaves. J. Exp. Bot. 58, 3395-3406 (2007). 